\title{
Looking Below the Sacrococcygeal Joint in Patients with Coccydynia (Coccyx Pain)
}

\author{
Patrick M. Foye ${ }^{1}\left[\right.$ Christopher A. Varghese ${ }^{1} \cdot$ Rustambir Singh $^{1}$
}

Received: 16 December 2019 / Accepted: 18 December 2019 / Published online: 13 January 2020

(c) Indian Orthopaedics Association 2020

Sir,

We applaud your journal and authors Gupta, Agarwal, and Baruah, on the very educational study titled, "Magnetic Resonance Measurements of Sacrococcygeal and Intercoccygeal Angles in Normal Participants and those with Idiopathic Coccydynia" [1].

We found it very interesting that this research showed that the sacrococcygeal angle was not significantly different between patients with idiopathic coccydynia as compared with non-symptomatic controls. Combined with prior research showing that the sacrococcygeal joint is fused in $51 \%$ of patients with idiopathic coccydynia [2], we feel that these studies suggest that the sacrococcygeal joint is not the primary source of pain in most of these patients. This further implies the importance of assessing carefully for pain generators specifically at the lower coccyx. Having evaluated thousands of coccydynia patients at our Coccyx Pain Center, we have very commonly found that performing lateral view radiographs specifically done using coned-down (collimation) views given better visualization of these lower, smallersized coccygeal bones (as compared with non-collimated radiographs), often revealing the source of pain.

We thank Gupta, Agarwal, and Baruah, for their research in this area, which we feel supports the importance of looking below the sacrococcygeal joint when evaluating and treating patients with tailbone pain.

\section{References}

1. Gupta, V., Agarwal, N., \& Baruah, B. P. (2018). Magnetic resonance measurements of sacrococcygeal and intercoccygeal angles in normal participants and those with idiopathic coccydynia. Indian Journal of Orthopaedics, 52, 353-357.

2. Postacchini, F., \& Massobrio, M. (1983). Idiopathic coccygodynia. Analysis of fifty-one operative cases and a radiographic study of the normal coccyx. Journal of Bone and Joint Surgery: American, 65, 1116-1124.
Patrick M. Foye

Doctor.Foye@gmail.com

1 Rutgers New Jersey Medical School, 90 Bergen St, D.O.C. Suite 3100, Newark, NJ 07103-2425, USA 